\title{
Assessment of the Effects of Increasing Levels of Physiological Realism in the Computational Fluid Dynamics Analyses of Implanted Coronary Stents
}

\author{
Jonathan Murphy \\ Technological University Dublin, jonathan.murphy@tudublin.ie \\ Fergal Boyle \\ Technological University Dublin, fergal.boyle@tudublin.ie
}

Follow this and additional works at: https://arrow.tudublin.ie/engschmeccon

Part of the Biomedical Engineering and Bioengineering Commons

\section{Recommended Citation \\ Murphy, J., Boyle, F.: Assessment of the Effects of Increasing Levels of Physiological Realism in the Computational Fluid Dynamics Analyses of Implanted Coronary Stents. Annual International Conference of the IEEE Engineering in Medicine and Biology Society. 2008. doi:10.1109/IEMBS.2008.4650559}

This Conference Paper is brought to you for free and open access by the School of Mechanical and Design Engineering at ARROW@TU Dublin. It has been accepted for inclusion in Conference Papers by an authorized administrator of ARROW@TU Dublin. For more information, please contact arrow.admin@tudublin.ie, aisling.coyne@tudublin.ie,gerard.connolly@tudublin.ie. Funder: Department of Mechanical Engineering, Technological University Dublin (DIT)and the Irish Research Council for Science Engineering and Technology (IRCSET)

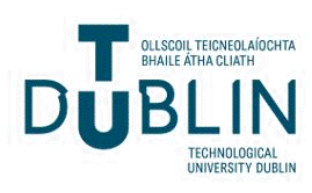




\title{
Assessment of the Effects of Increasing Levels of Physiological Realism in the Computational Fluid Dynamics Analyses of Implanted Coronary Stents
}

\author{
J. Murphy and F. Boyle
}

\begin{abstract}
Coronary stent implantation can improve blood flow in an artery that has been narrowed by the build up of arterial plaque. However, the implantation of the stent will change the geometry of the vessel wall. The haemodynamic effects of the stents presence and alteration of the vessel wall are unclear. The redistribution of flow induced vessel wall shear stress (WSS) and wall shear stress gradient (WSSG) may directly contribute to restenosis (re-blockage). Computational fluid dynamics (CFD) is used extensively to identify these parameters in stented vessels. However, simplifications to the model of the stented artery are common. In this paper, computational domains of stented arteries with increasing levels of physiological realism are created. CFD is used to predict the WSS and WSSG for each set of computational domains. Finally, the results show that certain simplifications are not valid for CFD analyses of implanted coronary stents.
\end{abstract}

\section{INTRODUCTION}

The accumulation of fatty cells in the wall of an artery is commonly referred to as a stenosis, a blockage that can significantly reduce the blood flow through an artery. The development of one or more stenoses in the arteries which supply blood to the cardiac muscles is a condition known as coronary artery disease (CAD). CAD deprives the cardiac muscles of crucial oxygen and nutrients. In the early $1990 \mathrm{~s}$ coronary stents were introduced to restore blood flow to the heart muscle in patients with CAD. A stent is a tubular scaffold which can be inserted into a diseased artery to relieve the narrowing caused by a stenosis. However, the success of the stenting procedure is limited by a process known as restenosis.

Restenosis is the excessive growth of new tissue in the stented segment which can re-block the artery. The success of the stenting procedure depends on the severity of the restenosis. The growth of new tissue is termed neointimal hyperplasia and has been shown to be dependant on several factors including arterial injury [1], areas of flow induced low wall shear stress (WSS) less than $0.5 \mathrm{~N} / \mathrm{m}^{2}$ [2], areas of flow induced high wall shear stress gradients (WSSG) higher

Manuscript received April 5, 2008. This study has been funded by the Department of Mechanical Engineering, DIT, and also by the Embark Initiative managed by the IRCSET as part of the Irish National Development Plan).

J. Murphy is a PhD student in the Mechanical Engineering Department at the Dublin Institute of Technology (e-mail: jonathan.murphy@ dit.ie).

F. Boyle is a senior lecturer in the Mechanical Engineering Department at the Dublin Institute of Technology (e-mail: fergal.boyle@dit.ie). than $200 \mathrm{~N} / \mathrm{m}^{3}$ [2], as well as other patient specific medical factors such as diabetes mellitus.

Computational fluid dynamics (CFD) has been used extensively to predict areas of low WSS and high WSSG in stented arteries [3-6]. However, the unrealistic assumption in the computational models that the stented segment retains a perfectly circular cross section after stent implantation is implicit to these investigations. A recent CFD investigation [7] of a stented artery compared a computational model using the circular cross section assumption with a computational model with simplified arterial prolapse and found a $300 \%$ difference in maximum WSSG results. In practice, stents are oversized by a factor of approximately $10 \%$ to the nominal diameter of the diseased artery for maximum effectiveness [8]. This aspect of stent implantation is also frequently overlooked in CFD investigations [3-6].

In this work, simple, oversized, and oversized with prolapse computational domains are created for the left anterior descending (LAD) coronary artery implanted separately with the Gianturco-Roubin II (GR-II) coil stent (Cook, USA) and with the Palmaz-Schatz (PS) slotted tube stent (Johnson \& Johnson, USA). CFD is used to predict the blood flow in these computational domains. Finally, the results of the CFD analyses are presented in the form of predicted WSS and WSSG acting on the arterial tissue for all six test cases.

Section II describes the methodology used to create the simple, oversized and oversized with prolapse computational domains.

Section III describes the methodology for the CFD simulations. Results for simple, oversized, and oversized with prolapse models are provided for both stents in Section IV.

\section{GENERATION OF COMPUTATIONAL DOMAINS}

\section{A. Introduction}

The computational domain represents the artery lumen. It is bounded by the artery wall and the implanted stent and is limited to a short distance proximal and distal to the stented region.

\section{B. Computational Domains for Simple Artery with Stent}

Idealised cylindrical arteries are constructed using ANSYS Workbench and the stent models with $3.0 \mathrm{~mm}$ inner diameters are cut from the arteries to produce computational domains. 
This represents the arteries implanted with either stent as shown in Figure 1 below. The inner artery diameters in the GR-II model and the PS model are $3.152 \mathrm{~mm}$ and $3.127 \mathrm{~mm}$ respectively to coincide with the outer diameters of the stents.

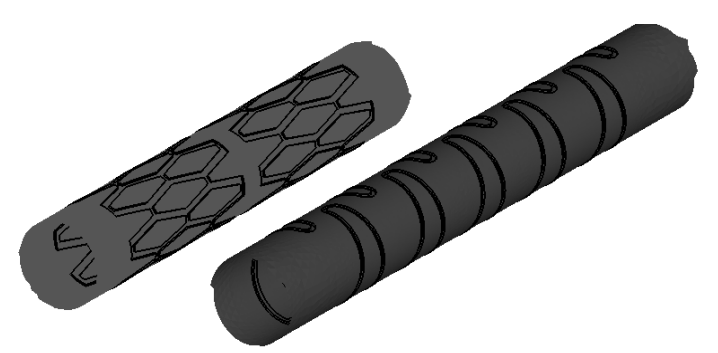

Figure 1: Simple computational models of coronary artery implanted with the $3.0 \mathrm{~mm}$ : (a) PS coronary stent, (b) GR-II coronary stent.

Additional length (AL) is added proximal and distal to the stented section to ensure the region of interest is not affected by the inlet and outlet boundary flow conditions applied in the CFD analyses. The additional length is provided by the formula

$$
A L=0.06 \times \operatorname{Re} \times D \approx 21 \mathrm{~mm}
$$

where $\mathrm{D}$ is the artery diameter and $\mathrm{Re}$ is the Reynolds number.

C. Computational Domains for Simple Artery with Oversized Stent

Stents are typically implanted with a stent-to-artery diameter ratio range of $1.1-1.2: 1$ to achieve maximum luminal patency and as an upper limit to prevent vascular damage during deployment [8].

Computational domains are created to represent the arteries implanted with stent models with $3.5 \mathrm{~mm}$ inner diameters. The diameters of the unstented sections are the same as in the simple implanted stent models.

\section{Computational Domains for Artery with Oversized Stent and Prolapse}

It is unrealistic to assume a stented segment of an artery retains an ideal cylindrical shape due to the elastic properties of the arterial wall tissue. Intravascular ultrasound has been widely used to show there will be tissue prolapse between the stent wires. This section describes a novel and efficient methodology to numerically predict tissue prolapse in a stented segment of an artery. The versatility of this methodology is then demonstrated by its application to the PS and GR-II stents which have two highly contrasting stent designs.

The initial step is to take Young's equation [10] which uses a cosine function to define the shape of a stenosis and apply it to predict prolapse between two stent wires. The prolapse equation applied between the wires is then given by

$$
\frac{R}{R_{o}}=1-\frac{\delta}{2 R_{o}}\left\{1+\cos \frac{2 \pi}{L}\left(z-\frac{L}{2}\right)\right\}
$$

where $\mathrm{L}$ is the distance between two stent wires, $\delta$ is the maximum protrusion height of the prolapse, $R_{o}$ is the inner radius of the healthy artery and $\mathrm{z}$ and $\mathrm{R}$ are co-ordinate variables as shown in Figure 2 below.

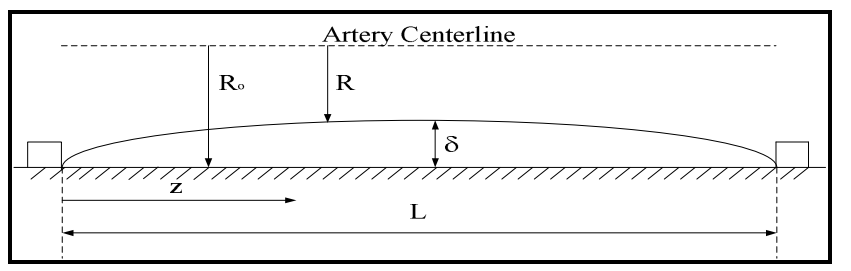

Figure 2: Protrusion of arterial prolapse between two stent wires from the artery wall as described by the prolapse equation.

Equation 2 above is modified to predict tissue prolapse in a stented artery by setting the prolapse maximum protrusion height as a function of the intra-wire spacing

$$
\delta=C L
$$

where $\mathrm{C}$ is the coefficient of prolapse derived from data provided by Prendergast et al. [9] and shown in Figure 3.

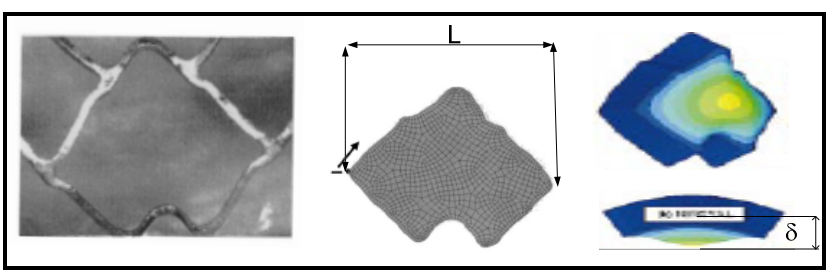

Figure 3: Finite Element Analysis of the NIROYAL stent (Boston Scientific) conducted by Prendergast et al. [9] and providing maximum protrusion height $(\delta)$ and supported length of tissue (L).

To predict the prolapse of a given stent, the scaffolding properties of the geometry must first be classified as circumferentially or axially dominant. The GR-II stent has axially dominant scaffolding properties as the shortest distance between two stent wires is in the axial direction. Conversely the PS stent is circumferentially dominant as the shortest distance between its stent wires is in the circumferential direction. The modified prolapse equation which combines Equations 2 and 3 is applied to the dominant scaffolding direction for each stent model.

A further modification of the equation must be applied to account for the secondary scaffolding direction of each stent. In this case it is assumed that the third supporting wire begins to influence the prolapse at half the distance $\mathrm{L}$ between the wires in the primary direction. The final prolapse equation is written

$$
\frac{R}{R_{o}}=1-\frac{X \delta}{2 R_{o}}\left\{1+\cos \frac{2 \pi}{L}\left(z-\frac{L}{2}\right)\right\}
$$

where $\mathrm{X}$ decreases linearly from one to zero in the secondary direction, providing zero prolapse at the third supporting stent wire as shown in Figure 4 overleaf.

This methodology for simulating prolapse in a stented artery is applied to the computational domains representing 
the arteries implanted with the oversized PS and GR-II stents.

The two models of the implanted artery which include the effect of oversizing and prolapse are shown Figures 5a and $5 b$.

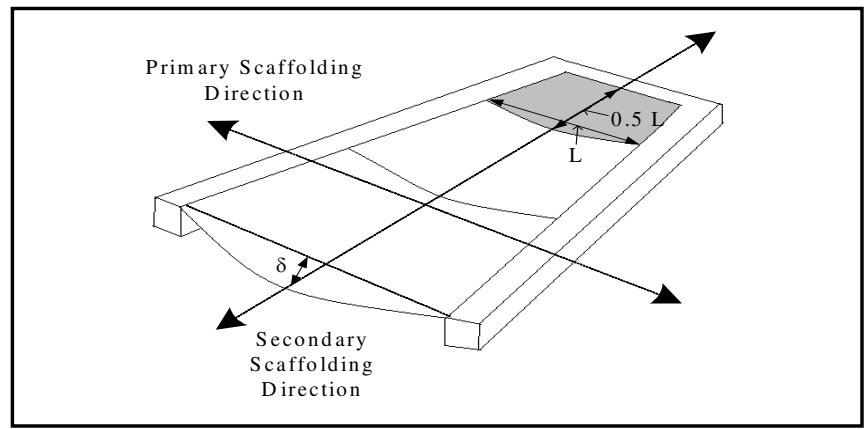

Figure 4: Illustration of the area (shaded) influenced by the stent wire in the secondary scaffolding direction with the PS stent.

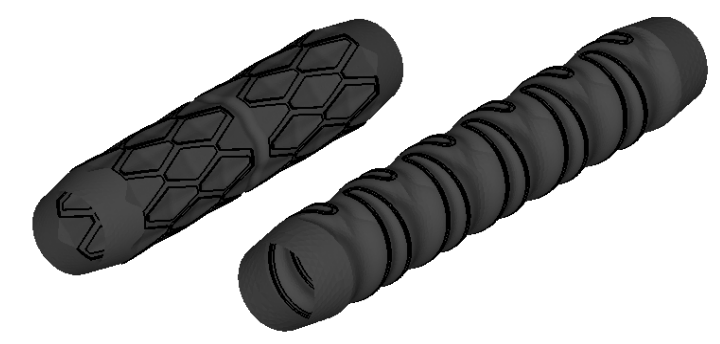

Figure 5: Computational models including over sizing and prolapse of coronary artery implanted with the 3.0mm: (a) PS coronary stent; (b) GR-II coronary stent.

\section{COMPUTATIONAL FLUID DYNAMICS}

\section{A. Introduction}

CFD is a process whereby real-life fluid flows are simulated using numerical methods to solve the governing equations of fluid dynamics. CFD is a relatively new branch of fluid dynamics commonly regarded as the "third" technique for solution of fluid flow problems, complementing, but not replacing the well-established approaches of theory and experiment. CFD finds its niche in modelling fluid flows that are difficult or impossible to model using theory and are complex, time consuming or expensive to measure experimentally.

\section{B. Governing Equations of Fluid Mechanics}

All simulations involve steady incompressible laminar flow which requires the CFD code to solve the conservation of mass and momentum equations, the general form of which are listed as Equations (5) and (6) respectively:

$$
\begin{gathered}
\frac{\partial \rho}{\partial t}+\vec{\nabla} \cdot(\rho \vec{V})=0 \\
\frac{\partial \rho \vec{V}}{\partial t}+\vec{\nabla} \cdot(\rho \vec{V} \otimes \vec{V})=-\vec{\nabla} p+\vec{\nabla} \cdot(\tau)+\rho \vec{g}+\vec{F}
\end{gathered}
$$

At low shear rates blood exhibits the non-Newtonian behaviour of variable viscosity which is dependant on the shear rate. The non-Newtonian nature of the flow is accommodated by using the Carreau model given in Equation 7:

$$
\mu=\mu_{\infty}+\left(\mu_{0}-\mu_{\infty}\right)\left[1+(\gamma \lambda)^{2}\right]^{\left(\frac{q-1}{2}\right)}
$$

where $\gamma$ is the rate of deformation tensor.

\section{Boundary Conditions}

Boundary conditions must be applied at all exterior boundaries of the computational domain to define the flow. The same set of boundary conditions are applied for all simulations. A fully developed axial velocity profile is applied at the inlet given by:

$$
V=V_{\text {Max }}\left(1-\frac{r^{2}}{R^{2}}\right)
$$

where the variable $r$ is the radial coordinate measured from the centreline and $\mathrm{R}$ is the wall radius. $\mathrm{V}_{\mathrm{Max}}$ is the maximum centreline velocity given a value which corresponds to a blood volume flow rate of $55 \mathrm{ml} / \mathrm{min}$ to simulate resting conditions in the LAD coronary artery.

A fixed static pressure of zero Pascals was applied at the outlet of the domain to allow the software to calculate the velocity at this plane.

The no-slip boundary condition was applied on all surfaces representative of the artery wall and the stent wires.

\section{RESULTS}

\section{A. Wall Shear Stress}

The indices for areas exposed to low WSS $\left(<0.5 \mathrm{~N} / \mathrm{m}^{2}\right)$ for all six models are provided in Table 1 overleaf. The oversized models for both stents showed a much greater normalised area subjected to low WSS than the simple models with an increase from $11.1 \%$ to $24.1 \%$ for the GR-II stent and from $3.5 \%$ to $19.7 \%$ for the PS stent. The low WSS occurs primarily around the stent wires in the simple models. The oversized models predict a large area of low WSS in the proximal stented region for both stents as shown in Figure 6. The models with oversizing and prolapse predict a modest increase in normalised stent area subjected to low WSS compared to the oversized models for both stents $(2.1 \%$ and $1.3 \%$ for the GR-II and PS respectively). The GR-II stent had a greater amount of normalised area exposed to low WSS for all simulations

\section{B. Wall Shear Stress Gradient}

The normalised area exposed to high WSSG (>200 N/m $\left.{ }^{3}\right)$ increases from the simple to the oversized models as shown in Figure 7 (increases of $7.1 \%$ and $7.7 \%$ for the GR-II and PS respectively). This increase occurs primarily in the proximal and distal stented regions for both models. The WSSG indices show a further increase from the oversized to the oversized with prolapse models $(31.7 \%$ and $21.4 \%$ for the GR-II and PS respectively). The increase occurs over almost the entire stented region for both stent models due to the haemodynamic effect of the prolapse tissue. 
Table 1: Indices of wall shear stress

\begin{tabular}{|l|c|c|c|c|c|c|}
\hline \multicolumn{1}{|c|}{ Stent Type } & \multicolumn{3}{c|}{ Gianturco - Roubin II } & \multicolumn{3}{c|}{ Palmaz - Schatz } \\
\hline Computational Model & Simple & Oversized & $\begin{array}{c}\text { Oversized with } \\
\text { Prolapse }\end{array}$ & Simple & Oversized & $\begin{array}{c}\text { Oversized with } \\
\text { Prolapse }\end{array}$ \\
\hline Normalised area exposed to WSS $\mathbf{< . 5 ~ N / \mathbf { m } ^ { \mathbf { 2 } }}$ & 0.111 & 0.241 & 0.262 & 0.035 & 0.197 & 0.210 \\
\hline Normalised area exposed to WSSG $\mathbf{> 2 0 0} \mathbf{~ N / \mathbf { m } ^ { \mathbf { 3 } }}$ & 0.537 & 0.608 & 0.925 & 0.662 & 0.739 & 0.953 \\
\hline
\end{tabular}

\section{CONCLUSION}

The results clearly show a difference in WSS and WSSG distributions between the simple, oversized and oversized with prolapse models for both stents. In light of the fact that these variables play a crucial role in dictating the arteries response to the stenting procedure, future CFD models must include the important factors presented in this paper to predict accurate and realistic results.

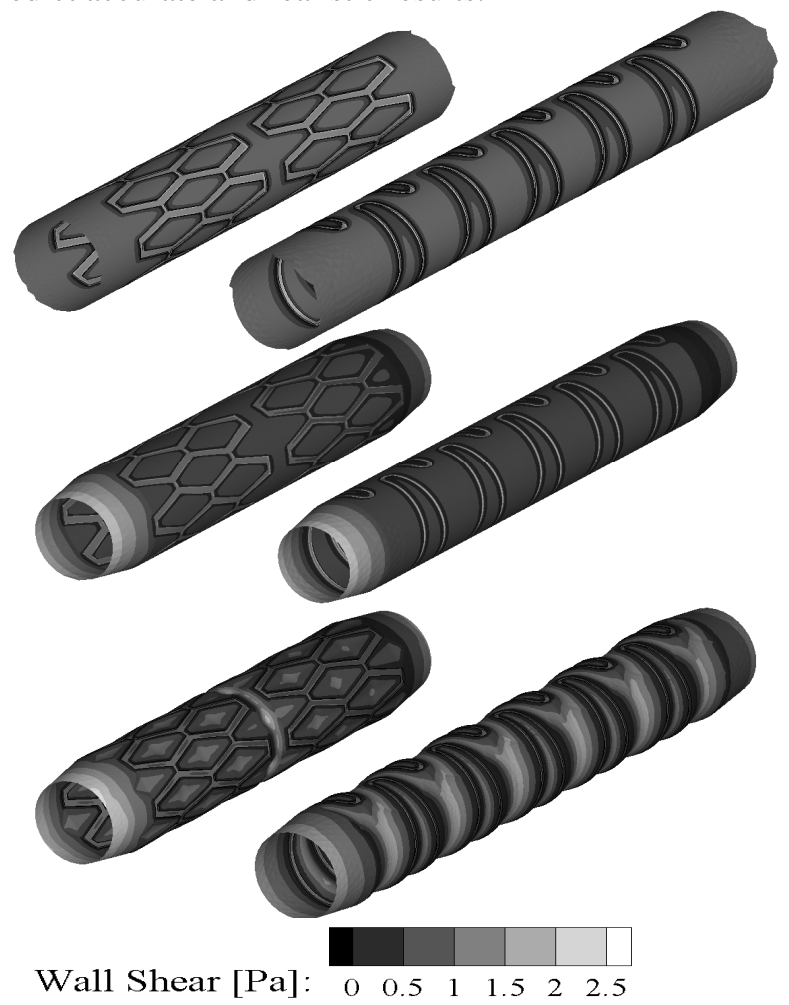

Figure 6: Contours of wall shear stress for all six computational models.

\section{References}

[1] R. Schwartz, \& D. R. Holmes, Pigs, Dogs, Baboons, and Man; Lessons in Stenting from Animal Studies, Journal of Interventional Cardiology, 7(1), 1994, 355-368.

[2] J. F. LaDisa, L. E. Olson, R. C. Molthen, D. A. Hettrick, P. F. Pratt, M. D. Hardel, J. R. Kersten, D. C. Warltier, \& P. S. Pagel, Alterations in Wall Shear Stress Predict Sites of Neointimal Hyperplasia After Stent Implantation in Rabbit Iliac Arteries, American Journal of Physiology, 288, 2005, H2465-H2475.

[3] D. Rajamohan, R. K. Banerjee, L. H. Back, A. A. Ibrahim, \& M. A. Jog, Developing Pulsatile Flow in a Deployed Coronary Stent, Journal of Biomechanical Engineering, 128(3), 2006, 347-359.

[4] J. L. Berry, A. Santamarina, J. E. Moore, S. Roychowdhury, \& W. D. Routh, Experimental and Computational Flow Evaluation of Coronary Stents, Annals of Biomedical Engineering, 28(1), 2000, 386-398.
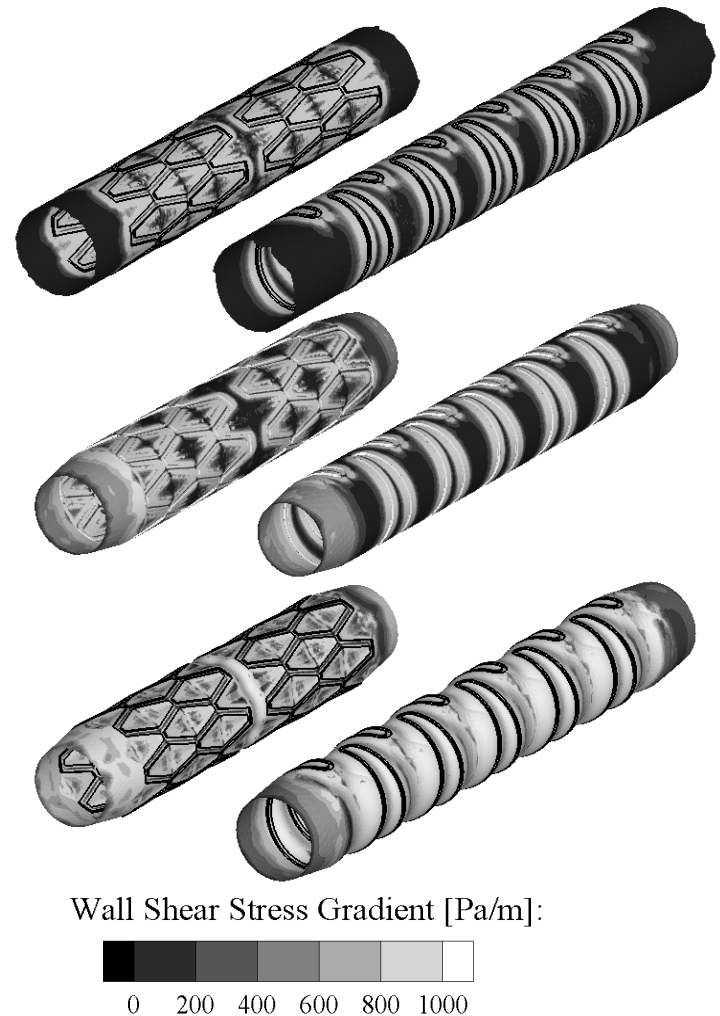

Figure 7: Contours of wall shear stress gradients for all six computational models.

[5] Y. He, N. Duraiswamy, A. O. Frank, J. E. Moore, Blood Flow in Stented Arteries: A Parametric Comparison of Strut Design Patterns in Three Dimensions, Journal of Biomechanical Engineering, 127(1), 2005, 637-647.

[6] J. F. LaDisa, G. Ismail, L. E. Olson, D. A. Hettrick, J. R. Kersten, D. C. Warltier, \& P. S. Pagel, Three-Dimensional Computational Fluid Dynamics Modeling of Alterations in Coronary Wall Shear Stress Produced by Stent Implantation, Annals of Biomedical Engineering, 31(8), 2003, 972-980.

[7] J. F. LaDisa, L. E. Olson, G. Ismail, D. A. Hettrick, J. R. Kersten, D. C. Warltier, \& P. S. Pagel, Circumferential Vascular Deformation After Stent Implantation Alters Wall Shear Stress Evaluated With Time Dependent 3D Computational Fluid Dynamics Models, Journal of Applied Physiology, 98, 2005, 947957.

[8] A. J. Lansky, G. S. Roubin, C. B. O'Shaughnessy, P. B. Moore, \& L. S. Dean, Randomized Comparison of the GR-II Stent and Palmaz-Schatz Stent for Elective Treatment of Coronary Stenoses, Circulation, 102(1), 2000, 1364-1368.

[9] P. J. Prendergast, C. Lally, S. Daly, A. J. Reid, T. C. Lee, D. Quinn, \& F. Dolan, Analysis of Prolapse in Cardiovascular Stents: A Constitutive Equation for Vascular Tissue and Finite Element Modelling, Journal Of Biomechanical Engineering, 125, 2003, 692-699.

[10] D. F. Young, Effect of a Time Dependant Stenosis on Flow Through a Tube, Journal of Engineering for Industry, 90(1), 1968, 248-254. 